\title{
Vitamin D status, body composition and physical activity in healthy young men
}

\author{
L. K. Forsythe, J. M. W. Wallace, E. Laird and M. B. E. Livingstone \\ Northern Ireland Centre for Food and Health, University of Ulster, Coleraine BT52 ISA, UK
}

Vitamin D deficiency and sub-optimal status are increasingly associated with unfavourable metabolic phenotypes including insulin resistance, type 2 diabetes and $\mathrm{CVD}^{(1)}$. It has been reported that vitamin $\mathrm{D}$ is sequestered by adipose tissue ${ }^{(2)}$, resulting in lower vitamin $\mathrm{D}$ status in overweight and obese individuals $\mathrm{s}^{(3,4)}$. The aim of the current study was to investigate the relationships between vitamin $\mathrm{D}$ status, body composition and physical activity (PA) in apparently healthy young men, aged 18-30 years, living in Northern Ireland.

A single fasting blood sample was taken from consenting volunteers $(n 121)$ and serum 25-hydroxycholecalciferol [25(OH)D, nmol/l] was quantified as a measure of vitamin D status using HPLC MS (API 4000, Chromsystems, USA). Height and weight were measured and BMI calculated. Fat mass (FM, kg) and fat-free mass (FFM, kg) were measured using total body dual-energy X-ray absorptiometry (DXA) scans (Lunar Prodigy, GE Healthcare, UK). Levels of total PA (MET, h/d), including time (h) spent per day in leisure-time PA (LPA) and sedentary activity (SA) were assessed using a self-reported questionnaire.

For the group, mean (SD) age, weight, BMI, FM, FFM, LPA, TV, PA and 25(OH)D were 23.1 (3.4) years, 78.5 (13.7) kg, 24.9 (4.0) kg/ $\mathrm{m}^{2}, 15.9$ (8.8) kg, 59.1 (6.6) kg, 1.7 (1.2) h/d, 3.2 (1.7) h/d, 25.0 (16.1) MET h/d and 30.6 (16.7) nmol/l, respectively.

\begin{tabular}{|c|c|c|c|c|c|c|}
\hline & $\begin{array}{c}25(\mathrm{OH}) \mathrm{D} \\
(\mathrm{nmol} / \mathrm{l})\end{array}$ & $\begin{array}{c}\text { BMI } \\
\left(\mathrm{kg} / \mathrm{m}^{2}\right)\end{array}$ & $\begin{array}{l}\text { FM } \\
(\mathrm{kg})\end{array}$ & $\begin{array}{c}\text { FFM } \\
(\mathrm{kg})\end{array}$ & $\begin{array}{l}\text { LPA } \\
\text { (h/d) }\end{array}$ & $\begin{array}{c}\text { SA } \\
(\mathrm{h} / \mathrm{d})\end{array}$ \\
\hline BMI $\left(\mathrm{kg} / \mathrm{m}^{2}\right)$ & 0.15 & & & & & \\
\hline FM $(\mathrm{kg})$ & -0.04 & $0.81 * *$ & & & & \\
\hline FFM (kg) & $0.26^{* *}$ & $0.56 * *$ & $0.27 * *$ & & & \\
\hline LPA (h/d) & $0.23^{*}$ & $0.32 * *$ & 0.11 & $0.28 * *$ & & \\
\hline SA (h/d) & -0.03 & -0.04 & 0.03 & -0.03 & -0.05 & \\
\hline PA (MET h/d) & 0.16 & $0.33 * *$ & 0.17 & $0.24 * *$ & $0.67 * *$ & -0.10 \\
\hline
\end{tabular}

Significant seasonal variation was observed in $25(\mathrm{OH}) \mathrm{D},(P=0.006$, ANOVA). Vitamin D status was significantly higher in those sampled in the summer months (June-August), compared to those in spring (Mar-May) or winter (November-January) $(P<0.05$, Tukey post hoc tests). After controlling for season and age, 25(OH)D concentration was positively correlated with FFM and also with LPA. BMI was positively correlated with both LPA and PA, an association driven by the correlations with FFM as opposed to FM.

In conclusion, in this group of healthy young males, vitamin D status was not associated with adiposity. In contrast vitamin D status was associated with FFM; an association, we speculate is explained by greater time spent outdoors among leaner volunteers. Improved vitamin D status would be an additional benefit of increasing outdoor physical activity and may contribute to the widely reported health benefits of PA.

This work was funded by the Department for Employment and Learning. Ethical approval was obtained from the University of Ulster Research Ethics Committee and the study was conducted according to the guidelines laid down in the Declaration of Helsinki.

1. Holick MF (2007) New Eng J Med 357, 266-281.

2. Wortsman J, Matsuoka LY, Chen TC et al. (2000) Am J Clin Nutr 72, 690-693.

3. Blum M, Dallal GE \& Dawson-Hughes B (2008) J Am College Nutr 27, 274-279.

4. Lagunova Z, Porojnicu AC, Lindberg F et al. (2009) Anticancer Res 29, 3713-3720. 